\title{
Erratum to: Two Decades of Value Change: The Crystallization of Meritocratic and Egalitarian Beliefs in the Czech Republic
}

\author{
Michael L. Smith • Petr Matějů
}

Published online: 9 November 2012

(C) Springer Science+Business Media New York 2012

\section{Erratum to: Soc Just Res \\ DOI 10.1007/s11211-012-0164-9}

The authors would like to apologize for an error in Graph 2 and in the description of Graph 2. The graph incorrectly depicts a weight of 1 in the path between selfemployment and meritocracy, as well as between unemployed and egalitarianism. The graph is incorrect because no such weights were used in the analysis published here. The correct graph is reproduced below.

In addition, we apologize that a comment by one of the co-authors about the above error was inadvertently published. The sentence beginning with "If you want to use this version of the diagram..." is a message between the co-authors that should not have been published.

Lastly, in the abstract, the phrase "In order words" should read "In other words."

The online version of the original article can be found under doi:10.1007/s11211-012-0164-9.

\footnotetext{
M. L. Smith ( ()

Institute of Sociology, Academy of Sciences of the Czech Republic,

Jilská 1, Praha 1 11000, Czech Republic

e-mail: michael.smith@soc.cas.cz

P. Matějů

University of Finance and Administration, Estonská 500,

Prague 10 10100, Czech Republic
} 


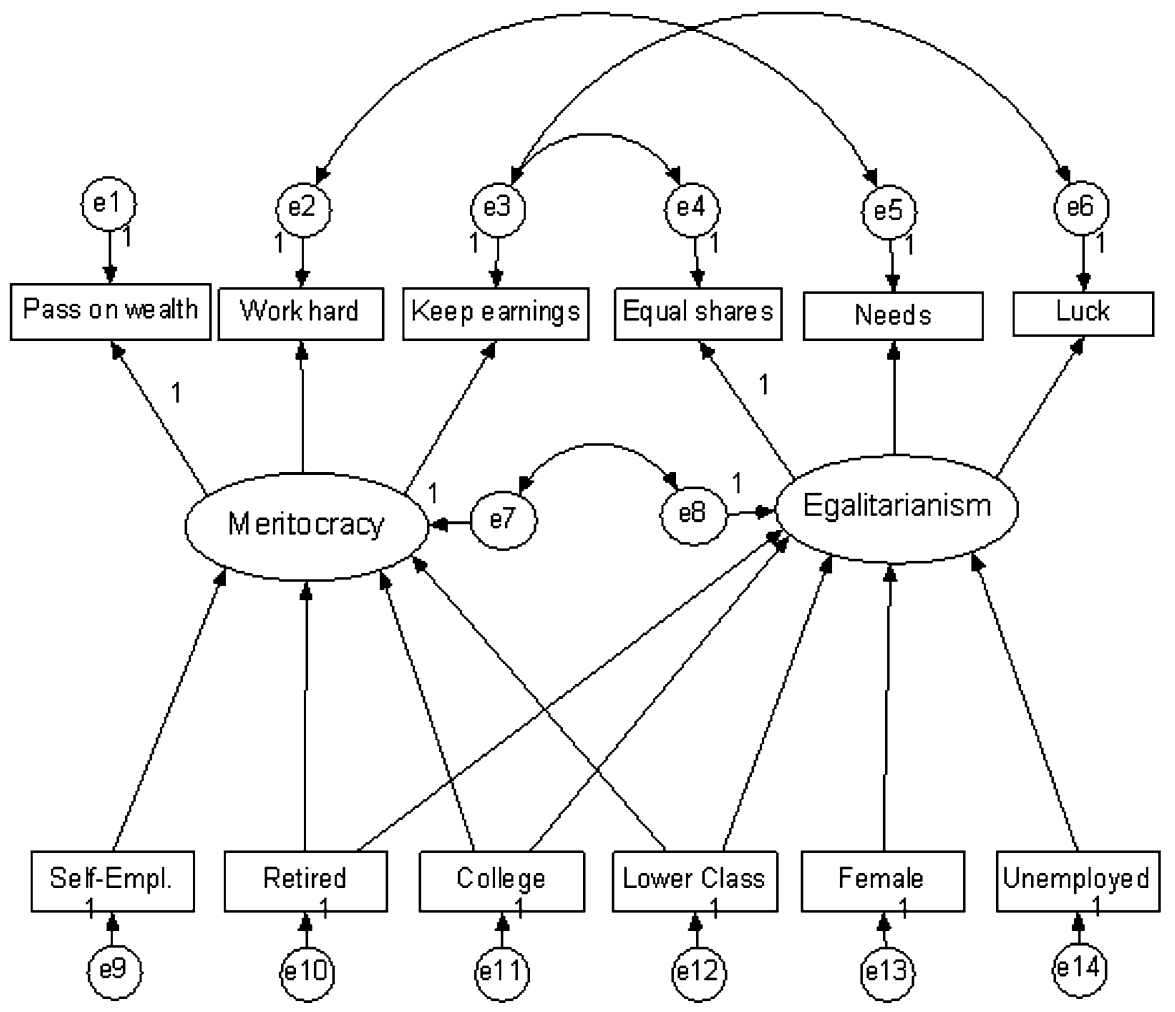

Graph 2 Structural model of the role of social stratification on justice ideologies 